\title{
Improving the efficiency of technological processes for the treatment of highly concentrated wastewater to ensure environmental safety
}

\author{
Svetlana Andreeva ${ }^{1 *[0000-0003-0734-4618]}$ \\ ${ }^{1}$ Kazan State University of Architecture and Engineering, 420043 Kazan, Russia
}

\begin{abstract}
The complexity of biochemical wastewater treatment is most often due to the presence of a large number of organic impurities, causing the death of the biological community of activated sludge microorganisms. Application of the method of lowering the $\mathrm{pH}$ of industrial effluents to minimum value reduces the solubility of organic substances in water, separating them into a separate layer of emulsified wastewater. In this case, the process of removing organic impurities from treated wastewater becomes the most accessible, but also requires solving the problems of technological and environmental safety. Dissolution of wastewater organic impurities separated into a separate layer a solvent - the extractant followed by the extraction of organic components extracted from it, reduces the level of wastewater pollution with organic substances according to the oxidation index (COD) to an acceptable level. The technology of the applied method allows for the final treatment using biological methods; and practically constructively mounts and build a new modernized technological line. Keywords. Wastewater treatment, technology, organic components, degree of purification, extractant, high-concentration wastewater.
\end{abstract}

\section{Introduction}

Issues of integrated wastewater treatment are especially relevant in recent years, due to the fact that environmental requirements for the degree of purification of water used by enterprises are constantly tightening, as well as the requirements to ensure the safety of the technological process $[1,2]$. Difficulties of solving the issues of wastewater treatment are certainly related to the complexity and variability of the composition, as well as the impressive economic costs of apparatus design and reagents. The diversity of systems by chemical composition and formation conditions dictates individual research for each case. Multicomponent composition of wastewater does not allow the use of standard water treatment technologies and requires a personalized approach to treatment methods [3-5].

The task of industrial wastewater treatment from dissolved organic substances is one of the most significant and at the same time difficult to solve $[6,7]$. In spite of the fact that not

"Corresponding author: saandreeva@mail.ru 
a few domestic and foreign developments are published annually on this topic, this problem cannot be considered as solved [8,9]. There are several reasons for this. Firstly, the systems are very diverse in their component composition and factors of formation and cause the need for separate studies for each specific case. Secondly, the chemical composition of effluents is most often not constant, due to the peculiarities of technological processes and the passage of a large number of side reactions. Thirdly, the technology of wastewater treatment itself requires compliance with certain conditions that are not always possible in practice. And another important reason for the urgent issue of wastewater treatment is the high cost of reagents and apparatus design. Often overlooked is the issue of environmental friendliness of the wastewater treatment process, because it is necessary to regenerate the used reagents, recycle or bury waste $[10,11]$. The combination of these reasons creates great difficulties in the organization of the complete water treatment process for most enterprises. Therefore, the search for new effective, environmentally friendly and economical methods of industrial wastewater treatment is still urgent [12-14].

As a rule, fundamental research on this problem considers model systems consisting of water and the main impurity [15-17]. The presence of accompanying substances in the effluent, causing the complexity of the component composition of the system in most cases is not taken into account. The difficulty of assessing and taking into account the mutual influence of such components on the processes going on inside the system complicate the process of wastewater treatment or make it impossible in practice [18-20]. Thus, substances present in wastewater in varying quantities and quality (dissociated and non-dissociated form) prevent the use of standard technologies of water treatment and require a comprehensive approach to the methods of treatment of wastewater with a complex composition [21-23].

\section{Materials and methods}

The experiments were conducted on real wastewater from styrene and propylene oxide production. The degree of purification of wastewater from organic components was determined by changing the water oxidation index (COD). Determination of COD value was carried out by the method, which in these experiments is based on the reaction of oxidation of organic substances in wastewater with potassium bichromate. The indicator of changes in the $\mathrm{pH}$ of wastewater was determined using a $\mathrm{pH}$ meter. Calcined wastewater residue was obtained by calcination of dry residue in a muffle furnace at $600{ }^{\circ} \mathrm{C}$. Chromatographic analysis was carried out on a gas chromatograph Chromatec - Crystal 5000.2 using a thermal conductivity detector and a capillary polar column with an inner diameter of $0.25 \mathrm{~mm}$ and length of $60 \mathrm{~m}$. The analysis was performed under the following conditions: helium carrier gas, carrier gas flow rate through the column $1 \mathrm{~cm}^{3} / \mathrm{min}$, evaporator temperature $200{ }^{\circ} \mathrm{C}$, sample volume triggered $1 \mu \mathrm{l}$, column temperature 70 to $200{ }^{\circ} \mathrm{C}$, thermal conductivity detector temperature $200{ }^{\circ} \mathrm{C}$. Processing of chromatograms was performed using the software package «Chromatec Analytical 3.1». The experiments were performed on different wastewater samples from the same styrene and propylene oxide production site with different values of $\mathrm{COD}, \mathrm{pH}$ and calcined residue.

\section{Results}

The results of the study in determining the chemical composition revealed that $30 \%$ of the components contained in the organic part of wastewater are considered to be volatile. Such substances are removed with water vapor during distillation. While the main part $(70 \%)$ is represented by components of organic compounds whose boiling point is above $180^{\circ} \mathrm{C}$. Such conclusions were drawn after distillation of the effluent to dryness. 
Further research showed that the main part of COD indicator is determined by chemical substances contained in the distillation cube residue. High values of oxidizability indicate significant content of organic substances in the effluent. Most of them are contained in the distillation cube residue, which means that it has a high boiling point and density.

Chromatographic analysis of the component composition of impurities in the effluent revealed that methyl phenyl carbinol, phenol, acetophenone are present in sufficiently large quantities.

As a result of the experiment, it was found that the introduction of concentrated sulfuric acid in wastewater allows separating a layer of organic components in water. Experiments have shown that the released organic substances are well soluble in organic solvents and can be extracted with their subsequent removal from the effluent.

\section{Discussion}

Examining wastewater from styrene production, we found that the main physico-chemical characteristics are not stable (Table1).

Table 1. Physico-chemical characteristics of styrene production wastewater.

\begin{tabular}{|c|c|c|c|c|c|c|}
\hline \multirow{2}{*}{ Indicators } & \multicolumn{6}{|c|}{ Samples } \\
\hline & 1 & 2 & 3 & 4 & 5 & 6 \\
\hline Appearance & $\begin{array}{l}\text { Brown } \\
\text { transparent } \\
\text { liquid }\end{array}$ & $\begin{array}{l}\text { Brown liquid } \\
\text { with an orange } \\
\text { film on the } \\
\text { surface }\end{array}$ & $\begin{array}{l}\text { Red } \\
\text { cloudy } \\
\text { liquid }\end{array}$ & $\begin{array}{l}\text { Colorless } \\
\text { liquid with } \\
\text { a dark oily } \\
\text { film on the } \\
\text { surface }\end{array}$ & $\begin{array}{l}\text { Yellow- } \\
\text { brown } \\
\text { turbid } \\
\text { liquid }\end{array}$ & $\begin{array}{c}\text { Dark } \\
\text { brown } \\
\text { liquid }\end{array}$ \\
\hline $\mathrm{pH}$ & 9.00 & 9.00 & 9.52 & 6.20 & 9.28 & 10.96 \\
\hline $\mathrm{COD}, \mathrm{gO}_{2} / 1$ & 92.30 & 74.44 & 94.20 & 31.22 & 57.71 & 892.00 \\
\hline Dry residue, $\mathrm{g} / 1$ & 48.10 & 32.40 & 44.70 & 13.10 & 18.60 & 97.00 \\
\hline $\begin{array}{l}\text { Hardened } \\
\text { residue, g/l }\end{array}$ & 17.90 & 18.70 & 17.20 & 6.70 & 7.50 & 42.00 \\
\hline
\end{tabular}

The table shows that the average value of the index of chemical oxygen demand (COD) varies over a wide range and can reach $900 \mathrm{~g} \mathrm{O}_{2} / \mathrm{L}$, indicating the presence of high concentrations of organic components in wastewater samples and their multi-component nature.

Our study is devoted to determining the conditions and the required depth of wastewater treatment, providing the greatest availability of effluents for further biodegradation.

To determine the nature of the component composition of the effluent, separation of impurities was performed by distilling the effluent to dryness. More detailed studies in determining the chemical composition reveals that $30 \%$ of the components are contained in the organic part of the effluent, which is considered to be volatile. During distillation such substances are removed with water vapor. The main part of components $(70 \%)$ is represented by components of organic compounds whose boiling point is above $180{ }^{\circ} \mathrm{C}$. Such conclusions were drawn after distillation of the effluent to dryness. The results are presented in Table 2.

Table 2. Results of wastewater distillation $\left(\mathrm{COD}=714 \mathrm{mgO}_{2} / \mathrm{L} ; \mathrm{pH}=8,90\right)$.

\begin{tabular}{|l|c|c|}
\hline \multicolumn{1}{|c|}{ Components } & Boiling point, ${ }^{0} \mathrm{C}$ & Quantity, \% vol \\
\hline Condensation & up to 100 & 30 \\
\hline Distillation residue & over 180 & 70 \\
\hline
\end{tabular}

Table 3. COD values of volatile and heavy constituents of waste water.

\begin{tabular}{|l|c|}
\hline \multicolumn{1}{|c|}{ Components } & COD indicator, $\mathrm{mgO}_{2} / \mathrm{l}$ \\
\hline Wastewater sample & 780 \\
\hline Waste water distillation condensate & 234 \\
\hline Waste water distillation condensate & 546 \\
\hline
\end{tabular}


Further studies showed that the main share of COD indicator was determined by chemical substances contained in the distillation cube residue (Table 3 ).

The distillation residue is a viscous oily mass of dark brown color. The data suggest that most of the impurities are organic compounds with a high boiling point and do not form azeotropic mixtures with water.

To determine the nature of the components extracted from the acidified waste water and remaining in the aqueous phase, chromatographic analysis was performed. Chromatograms are shown in Fig. 1-2.

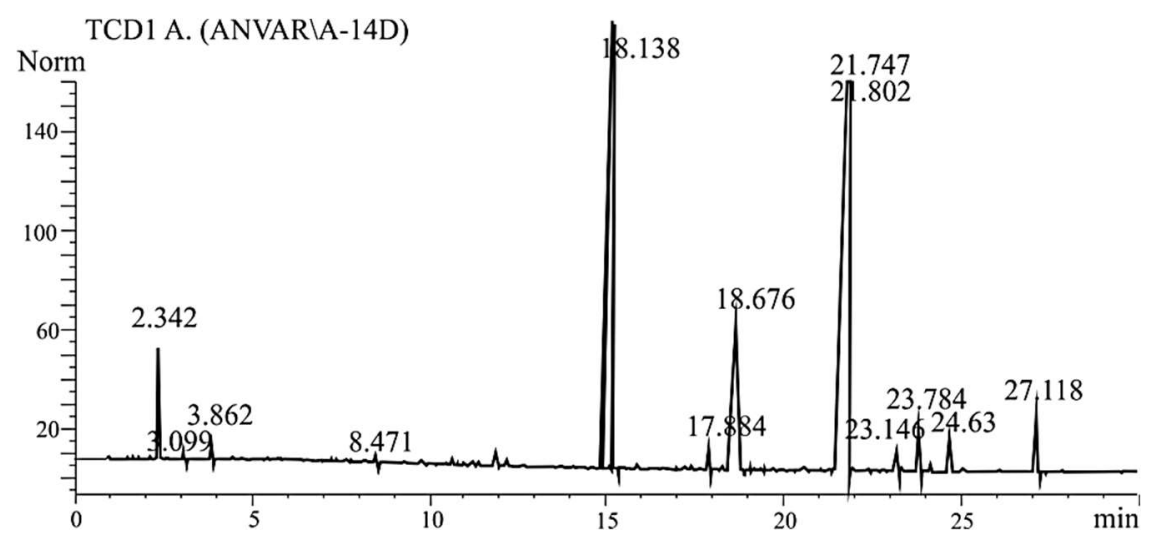

Fig. 1. Chromatograms of wastewater impurities in the organic phase.

The analysis has shown that the organic phase consists mainly of phenol (18676), methylphenylcarbinol (21747) and acetophenone (21802). The aqueous phase contains mainly ethanol (3115), phenol (18581), propylene glycol (9911) and methylphenylcarbinol (21408).

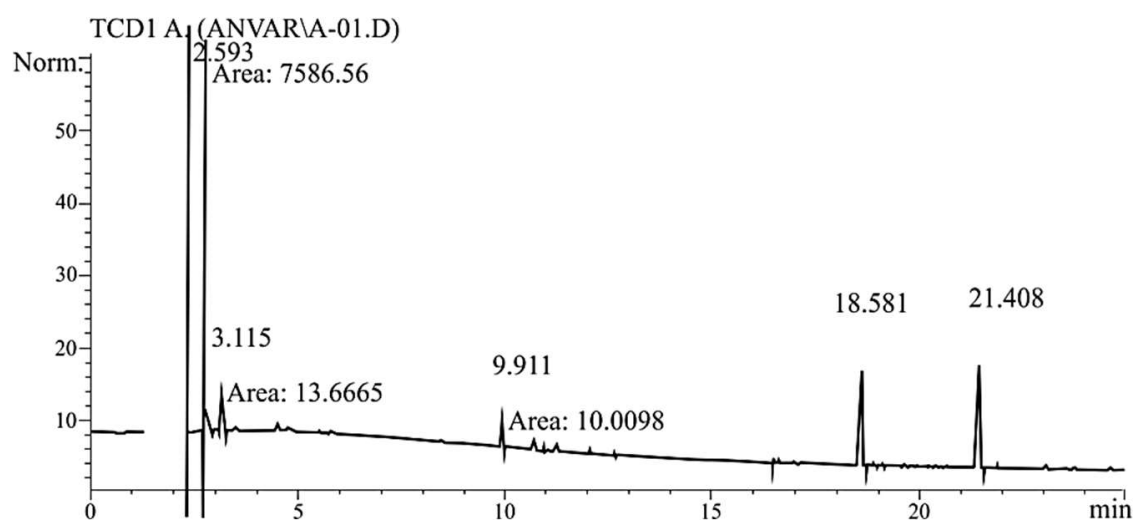

Fig. 2. Chromatograms of wastewater impurities in the aqueous phase.

Studies have found that the organic components extracted from the acidified effluent have densities slightly different from the density of water. In this regard, the organic components are poorly separable from the aqueous phase by simple sedimentation. In experiments, floating, sticking or smearing on the walls of the reaction vessel of the isolated organic components of the mixture was observed. It complicated the process of separating the impurities by simple sedimentation. For reliable extraction of isolated components it is necessary to use organic solvents. Phenol is the most toxic of the extracted components. Phenol has a detrimental effect on micro and macroorganisms, so the production effluent with this component is difficult to biologically decontaminate [24]. 
One of the effective ways of phenolic wastewater treatment is the extraction of phenols with organic solvents. Therefore, the selection of solvent was carried out taking into account the possibility of maximum extraction of phenols from wastewater in order to increase the effectiveness of further biological treatment. We compared the efficiency of effluent treatment with ethylbenzene and toluene. The results are shown in Fig. 3, 4.

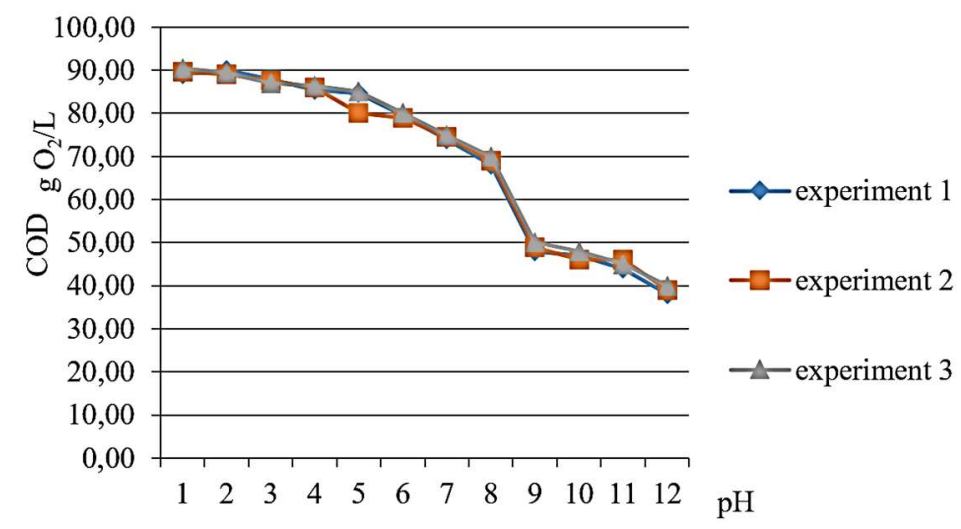

Fig. 3. Levels of COD indicator values when changing $\mathrm{pH}$ of wastewater during ethylbenzene extraction.

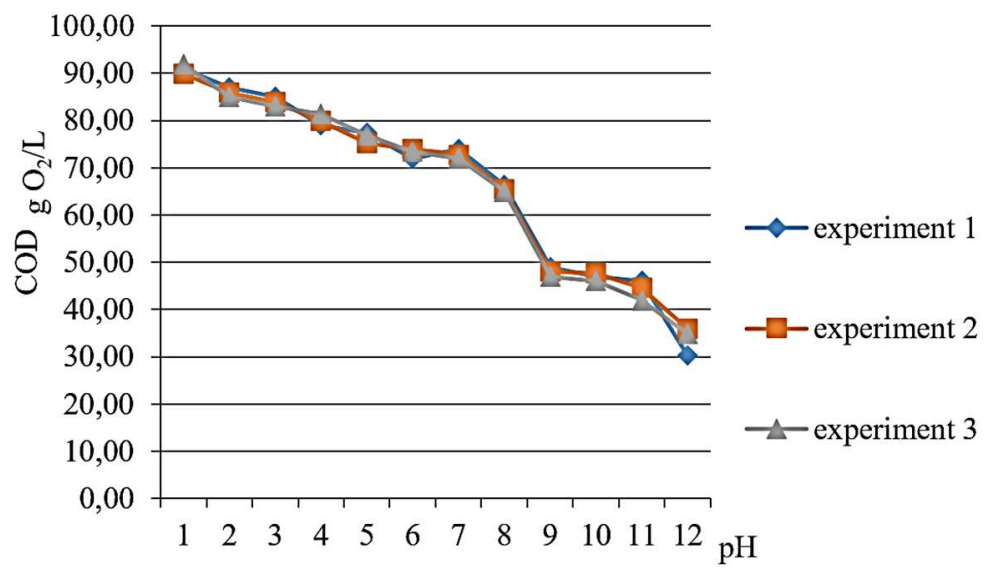

Fig. 4. Levels of COD indicator values when changing the $\mathrm{pH}$ of wastewater during toluene extraction.

Analysis of experimental data showed that in both cases, a significant decrease in the level of COD values occurs in the area of low $\mathrm{pH}$ values of treated water. Extraction with toluene allows to achieve a higher degree of wastewater purification from organic components. As a result of experiments on the physico-chemical treatment of wastewater COD value has decreased to $50 \mathrm{~g} / \mathrm{l}$, which significantly improved the biological characteristics and allowed to apply biological methods of further wastewater treatment. The organic impurities concentrated in the extractant are separated from the solvent by evaporation or distillation and can be utilized. Due to the fact that the extractant after use is used in the technological process of purification, there is a need for constructional modernization of existing technological areas of the wastewater treatment system. including production buildings, in which it is necessary to arrange new and improved technological lines of physical and chemical processes of extraction treatment, which provides the required standard level of safety of such effluents. 


\section{Conclusion}

1. To solve technological and environmental problems of wastewater treatment of complex composition from highly concentrated impurities, it is necessary to approach individually in relation to the specific amount of a particular pollution substance.

2 The efficiency of extraction purification of waste water containing organic components increases with decreasing $\mathrm{pH}$ (acidity) of hydrogen.

3 . The use of the extraction method in combination with acidification increases the level of environmental safety and efficacy of biological pretreatment of wastewater.

4. Modernization of existing technological areas of wastewater treatment system and improvement of technological lines of extraction treatment processes, contribute to achieving the required standard safety level of industrial wastewater treatment, especially for the biological community of activated sludge microorganisms.

5. For practical implementation of the developed technological processes it is necessary to provide design, construction and installation improvement of modernized technological lines of wastewater treatment.

\section{References}

1. Q. Ji, S. Tabassum, S. Hena, C. G. Silva, G. Yu, Z. Zhang, J. Clean. Prod. 126, 38 (2016). DOI: $10.1016 /$ j.jclepro.2016.02.147.

2. P.V. Nidheesh, C. Couras, A.V. Karim, H. Nadais, Chem. Eng. Commun, (2020). DOI: 10.1080/00986445.2020.1864626.

3. C.W. Xiong, C.Y. Ho, D. Qiao, Medziagotyra 26, (2020).

4. V.S. Izotov, R.A. Ibragimov, Inorg. Mater. 51, 187 (2015).

5. V.S. Solanki, B. Pare, P. Gupta, S.B. Jonnalagadda, R. Shrivastava, Asian J. Chem. 32, 2677 (2020). DOI: 10.14233/ajchem.2020.22806.

6. V. Turunen, J. Sorvari, A. Mikola, Chemosphere 193, 521 (2018). DOI: 10.1016/ j.chemosphere.2017.11.052.

7. R. Pedrazzani, G. Bertanza, I. Brnardić, Z. Cetecioglu, J. Dries, J. Dvarionienè, A.J. García-Fernández, A. Langenhoff, G. Libralato, G. Lofrano, B. Škrbić, E. MartínezLópez, S. Meriç, D.M. Pavlović, M. Papa, P. Schröder, K.P. Tsagarakis, C. Vogelsang, Sci. Total Environ 651, (2019). DOI: 10.1016/j.scitotenv.2018.10.027.

8. J. Karpińska, U. Kotowska, Water (Switzerland) 11, (2019). DOI: 10.3390/w11102017.

9. B.S. Rathi, P.S. Kumar, P.L. Show, J. Hazard. Mater. 409, (2021). DOI: 10.1016/ j.jhazmat.2020.124413.

10. M. Jain, A. Majumder, P.S. Ghosal, A.K. Gupta, J. Environ. Manage. 272, (2020). DOI: 10.1016/j.jenvman.2020.111057.

11. J.O. Drangert, Ambio 50, (2021). DOI: 10.1007/s13280-020-01373-1.

12. I. Oller, S. Malato, J.A. Sánchez-Pérez, Sci. Total Environ. 409, 4141 (2011). DOI: 10.1016/j.scitotenv.2010.08.061.

13. H.A.O. Alisawi, Appl. Water Sci. 10, (2020). DOI: 10.1007/s13201-020-1171-x.

14. S.J. Varjani, M. Chaithanya Sudha, (2018). DOI: 10.1007/978-981-10-7551-3_6.

15. T.S. Chun, M.A. Malek, A.R. Ismail, Am. J. Environ. Resour. Econ. 2, 22 (2017).

16. R.A. Ibragimov, E.V. Korolev, T.R. Deberdeev, V.V. Leksin, Struct. Concr. 20, (2019). DOI: $10.1002 /$ suco.201800008.

17. G.T. Daigger, Water Sci. Technol. 63, 516 (2011). DOI: 10.2166/wst.2011.252.

18. A. Serdarevic, A. Dzubur, Coupled Syst. Mech. 5, 21 (2016). DOI: 10.12989/csm.2016. 5.1.021.

19. V. Stroganov, E. Sagadeev, R. Ibragimov, L. Potapova, Constr. Build. Mater. 246, (2020). DOI: $10.1016 /$ j.conbuildmat.2020.118506. 
20. A. Abidli, Y. Huang, C.B. Park, Chemosphere 260, (2020). DOI: 10.1016/ j.chemosphere.2020.127586.

21. A. Khuzin, R. Ibragimov, (n.d.). DOI: 10.1016 / j.jobe.2020.102030.

22. J. Xu, X. Zheng, Z. Feng, Z. Lu, Z. Zhang, W. Huang, Y. Li, D. Vuckovic, Y. Li, S. Dai, G. Chen, K. Wang, H. Wang, J.K. Chen, W. Mitch, Y. Cui, Nat. Sustain. 4, (2021). DOI: 10.1038/s41893-020-00635-w.

23. Imaykin D.G., Ibragimov R.A., News KSUAE 2 (50) (2017).

24. K. Dhangar, M. Kumar, Sci. Total Environ. 738, (2020). DOI: 10.1016/j.scitotenv.2020. 140320 . 